Original Article

\title{
Improvement of tactile roughness discrimination acuity correlates with perception of improved hand function in patients after hand surgery
}

\author{
Shuhei Fujimoto, PT, MHSc $\left.{ }^{1,2}\right)^{* a}$, Noriko Kon, OT ${ }^{1,3) a}$ \\ 1) Kyoto University Graduate School of Medicine: Yoshidakonoemachi, Sakyo-ku, Kyoto \\ 606-8317, Japan \\ 2) Medley, Inc., Japan \\ 3) Kawakita Rehabilitation Hospital, Japan
}

\begin{abstract}
Purpose] The purpose of this study was to elucidate how well patients' perceptions related to the improvements in their hand function during hospitalization. [Subjects] Sixteen patients who were hospitalized after hand surgery. [Methods] Using the Japanese Society for Surgery of the Hand edition of the Quick-Disabilities of the Arm, Shoulder, and Hand questionnaire; tactile roughness discrimination acuity, motor imagery, motor function, sensory function, and pain of the upper limb were assessed at admission and discharge. Spearman's rank-order correlation coefficients were calculated using the differences in all assessment items at admission and discharge. A multiple regression analysis (stepwise method) was performed to investigate factors that correlated with improvements in Quick-Disabilities of the Arm, Shoulder, and Hand scores. [Results] The improvement of tactile roughness discrimination acuity was significantly associated with patient perception of improved hand function. [Conclusion] The results suggest that an improvement in tactile roughness discrimination acuity was most strongly correlated with patient perception of improved hand function.

Key words: Hand therapy, Tactile roughness discrimination, Rehabilitation
\end{abstract}

(This article was submitted Dec. 22, 2015, and was accepted Jan. 8, 2016)

\section{INTRODUCTION}

The primary goal of rehabilitation for post-hand surgery patients is to improve hand function and the frequency with which the affected hand is used in daily life ${ }^{1-4)}$. However, previous research has indicated that in the clinical setting, some patients do not experience any improvement in the frequency of affected hand use despite experiencing improved hand function.

Previous studies with stroke patients have reported that cognitions and perceptions had an important role for improving hand function and the frequency with which the affected hand was used ${ }^{5}$. Similarly, it was reported that breast cancer patients experienced a negative association between the kinesthetic sense and hand function ${ }^{6}$. Thus, hand functions may be recovered by the patients' perception and its cognition.

It was also hypothesized that the primary cause for this lack of improvement is a dissociation between actual hand function and patient perception of hand function. Therefore, an observational cross-sectional study was performed to investigate the factors related to patient perception of hand function ${ }^{7}$. The data revealed that patients who perceived a high degree of subjective hand motor function also displayed a high degree of tactile roughness discrimination acuity and experienced little pain in the affected hand ${ }^{7}$. However, it remains unclear whether the improvement in tactile roughness discrimination acuity, reduced pain, and the improvement in the patients' perception of hand function while being hospitalized are correlated. The

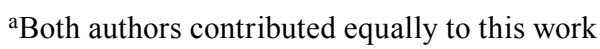
*Corresponding author. Shuhei Fujimoto (E-mail: Shuheifujimototbr@gmail.com)

(C2016 The Society of Physical Therapy Science. Published by IPEC Inc.

This is an open-access article distributed under the terms of the Creative Commons Attribution Non-Commercial No Derivatives (by-nc-nd) License $<$ http://creativecommons.org/licenses/by-nc-nd/4.0/>. 
purpose of the present study was to identify the physical functions and demographic variables related to improvements in patients' perception of hand function after hand surgery.

\section{SUBJECTS AND METHODS}

A total of 41 patients (32 males and 9 females; mean age $=48.6 \pm 10.4$ years) who underwent hand surgery between January and September 2014 in Japan were included in this study. Participants who experienced a loss of upper limb function due to a disorder unrelated to the injury at the surgical site were excluded from the study. In addition, 16 patients (13 males and 3 females; mean age $=47.4 \pm 14.4$ years) with an amputation or incomplete amputation (10), a tendon injury or tear (4), a dislocation (1), or other injury (1), to the dominant side (10) or the non-dominant side (6), were included. The mean length of the hospital stay was 11.4 days $\left( \pm 5.5\right.$ days). These characteristics are similar to those of patients in previous studies ${ }^{7)}$.

This study was conducted with the approval of the ethics committees of the participating hospitals. In accordance with the Helsinki Declaration, informed written consent was obtained from all subjects after providing them with a complete written description of the details of the study.

The patients' perception of hand function, tactile roughness discrimination acuity, motor imagery, motor function, sensory function, and pain were assessed.

The Japanese Society for Surgery of the Hand edition of the Quick-Disabilities of the arm, shoulder, and hand (QuickDASH) outcome measure was used to assess perceived hand function ${ }^{8}$.

The tactile roughness discrimination acuity test asks patients to discriminate between sandpapers of different roughness using a finger of the injured hand. Sandpapers of 80, 240, and 400 grits (JIS) were used in this study. A rater asked the subject to close their eyes and then place a finger of the injured hand on the sandpaper. The patients touched the sandpapers in random order. A correct answer was assigned when the patient was able to correctly identify all three sandpapers, and the percentage of correct answers was calculated from 10 attempts. Preliminary tests showed that the intra-rater reliability was high (interclass correlation coefficient $=0.98,95 \%$ confidence interval $=0.95,0.99$ ).

For the motor imagery test, subjects were asked to rate the clarity of first- and third-person motor imagery for flexion and extension of all fingers on the injured hand using a five-step scale. After performing each type of imagery once, patients selected the best response (difficult, somewhat difficult, neutral, somewhat easy, or easy) to the question, "Were you able to make a clear image?"

For the motor function test, the active range of motion of the fingers of the injured hand was measured. The obtained values were divided by the active range of motion angles of the fingers of the opposite hand, and the percentage of total active motion (\%TAM) was calculated.

For the sensory function, the subjects' static sensory threshold and two-point discrimination acuity were measured. The sensory threshold was assessed on a five-step scale using the Semmes-Weinstein monofilament test (SWM) ${ }^{9)}$. Two-point discrimination was performed using the static two-point discrimination test (s2PD) and the moving two-point discrimination test $(\mathrm{m} 2 \mathrm{PD})^{10,11)}$. The minimum distance (in $\mathrm{mm}$ ) at which discrimination was possible was measured.

Pain in the wrist was assessed using the self-administered Patient-Rated Wrist Evaluation (PRWE) questionnaire ${ }^{12)}$. Pain in the fingers was assessed using a separate PRWE in which the word "wrist" was replaced with the word "finger." Analysis was performed by totaling the wrist and finger pain scores. The assessment was performed twice, once at admission and once at discharge.

The clinical characteristics of the patients (age, gender, injured and dominant side, diagnosis, and number of days post-surgery) were obtained from the patients' medical records. All subjects underwent normal rehabilitation during hospitalization.

Spearman's rank-order correlation coefficients, using differences in QuickDASH, the tactile roughness discrimination acuity test, the motor imagery test, \%TAM, SWM, s2PD, m2PD, and PRWE at admission and discharge, were calculated to investigate whether improvements in QuickDASH scores during hospitalization were correlated with improvements in other factors. A multiple regression analysis (stepwise method) of the differences between QuickDASH scores at admission and discharge, as the dependent variables, and the differences between the other assessed items at admission and discharge, as the independent variables, was performed to assess the factors that were related to improvements in QuickDASH scores.

All analyses were performed using IBM SPSS Statistics ver. 21 for Windows (IBM, New York, America). Statistical significance was set at $5 \%$.

\section{RESULTS}

The descriptive statistics for all assessed items (at admission and discharge) are depicted in Table 1. Table 1 shows that QuickDASH scores had significantly improved at discharge compared to those at admission (mean difference 9.12, 95\% confidence interval $0.89,17.35, \mathrm{p}=0.03$ ). Similarly, \%TAM, tactile roughness discrimination acuity, and finger pain had improved significantly (Table 1).

The analysis of the correlation coefficients for all studied factors indicated that tactile roughness discrimination acuity had a high degree of correlation with the QuickDASH scores $(r=-0.57,95 \%$ confidence interval $=-0.83,-0.10$; Table 2$)$. Multiple regression analysis similarly showed that tactile roughness discrimination acuity was correlated with improvement in QuickDASH scores (Table 3). 
Table 1. Differences of measurements between admission and discharge

\begin{tabular}{lcccccc}
\hline Assessment & Admission & Discharge & \multicolumn{2}{c}{$\begin{array}{c}\text { Mean } \\
\text { difference }\end{array}$} & \multicolumn{2}{c}{$\begin{array}{c}\text { 95 Confidence } \\
\text { interval }\end{array}$} \\
\hline & & & & Lower & Upper \\
\hline QuickDASH (points) & $54.7 \pm 17.2$ & $45.6 \pm 16.3$ & 9.12 & 0.89 & 17.4 & $*$ \\
\%TAM (\%) & $50.6 \pm 16.5$ & $66.9 \pm 17.8$ & -20.7 & -31.9 & -9.55 & $* *$ \\
SWM & $3.94 \pm 1.44$ & $3.81 \pm 1.11$ & 0.27 & -0.25 & 0.79 \\
s2PD (mm) & $3.44 \pm 1.59$ & $3.63 \pm 1.26$ & 1.06 & -0.35 & 2.47 \\
m2PD (mm) & $7.97 \pm 10.1$ & $28.7 \pm 24.4$ & 0.31 & -0.32 & 0.95 & $*$ \\
Tactile roughness discrimination (\%) & $4.61 \pm 1.37$ & $4.34 \pm 1.33$ & -16.3 & -24.2 & -8.26 & $*$ \\
First-person motor imagery (points) & $9.56 \pm 5.91$ & $8.50 \pm 5.20$ & 0.13 & -0.65 & 0.90 & \\
Third-person motor imagery (points) & $5.44 \pm 2.25$ & $5.13 \pm 2.06$ & -0.19 & -0.89 & 0.52 & $*$ \\
Finger pain (points) & $68.5 \pm 17.6$ & $53.8 \pm 16.7$ & 14.8 & 1.86 & 27.6 & $*$ \\
Wrist pain (points) & $29.1 \pm 26.0$ & $25.1 \pm 24.8$ & 4 & -10.2 & 18.2 & \\
\hline
\end{tabular}

$* \mathrm{p}<0.05, * * \mathrm{p}<0.01$

m2PD: moving two-point discrimination test; s2PD: static two-point discrimination test; QuickDASH: Japanese Society of Surgery of the Hand edition of the Quick-Disabilities of the arm, shoulder, and hand questionnaire; \%TAM: percentage of total active motion; SWM: Semmes-Weinstein Monofilaments test

Table 2. Correlation coefficients for changes in QuickDASH scores and physical function variables

\begin{tabular}{|c|c|c|c|c|c|c|c|c|c|c|c|}
\hline Assessment & $\begin{array}{l}\text { Quick- } \\
\text { DASH }\end{array}$ & $\begin{array}{c}\text { Tactile } \\
\text { roughness } \\
\text { discrimi- } \\
\text { nation }\end{array}$ & $\begin{array}{c}\text { First- } \\
\text { person } \\
\text { motor } \\
\text { imagery }\end{array}$ & $\begin{array}{l}\text { Third- } \\
\text { person } \\
\text { motor } \\
\text { imagery }\end{array}$ & $\% \mathrm{TAM}$ & SWM & s2PD & $\mathrm{m} 2 \mathrm{PD}$ & $\begin{array}{l}\text { Finger } \\
\text { pain }\end{array}$ & $\begin{array}{l}\text { Wrist } \\
\text { pain }\end{array}$ & $\begin{array}{c}\text { Elapsed } \\
\text { days }\end{array}$ \\
\hline \multicolumn{12}{|l|}{ QuickDASH } \\
\hline $\begin{array}{l}\text { Tactile roughness } \\
\text { discrimination }\end{array}$ & $-0.57^{*}$ & & & & & & & & & & \\
\hline First-person motor imagery & -0.13 & -0.2 & & & & & & & & & \\
\hline Third-person motor imagery & -0.13 & -0.04 & 0.34 & & & & & & & & \\
\hline$\%$ TAM & -0.16 & 0.04 & -0.18 & -0.47 & & & & & & & \\
\hline SWM & -0.35 & 0.04 & 0.22 & 0.08 & -0.22 & & & & & & \\
\hline s2PD & -0.04 & -0.46 & 0.42 & -0.07 & -0.25 & $0.54^{*}$ & & & & & \\
\hline $\mathrm{m} 2 \mathrm{PD}$ & 0.19 & -0.24 & 0.12 & -0.3 & -0.1 & 0.45 & $0.66^{* *}$ & & & & \\
\hline Finger pain & 0.02 & -0.13 & -0.08 & 0.42 & 0.04 & -0.43 & $-0.62 *$ & $-0.62 *$ & & & \\
\hline Wrist pain & 0.05 & -0.44 & -0.4 & 0.23 & -0.19 & 0.1 & -0.48 & -0.04 & 0.23 & & \\
\hline Elapsed days & 0.06 & 0.13 & -0.01 & 0.18 & 0 & 0.06 & -0.02 & 0.16 & -0.28 & 0.08 & \\
\hline
\end{tabular}

${ }^{*} \mathrm{p}<0.05, * * \mathrm{p}<0.01$

m2PD: moving two-point discrimination test; s2PD: static two-point discrimination test; QuickDASH: The Japanese Society of Surgery of the Hand edition of the Quick-Disabilities of the arm, shoulder, and hand questionnaire; \%TAM: percentage of total active motion; SWM: Semmes-Weinstein Monofilaments test

Table 3. Multiple regression analysis using QuickDASH scores as the dependent variable

\begin{tabular}{lcccc}
\hline \multirow{2}{*}{ Assessment } & $\begin{array}{c}\text { Partial regression } \\
\text { coefficient }\end{array}$ & $\begin{array}{c}\text { Standard partial } \\
\text { regression coefficient }\end{array}$ & \multicolumn{2}{c}{$95 \%$ Confidence interval } \\
\cline { 4 - 5 } Tactile roughness discrimination acuity* & -0.55 & -0.53 & -1.05 & Upper \\
\hline
\end{tabular}

$* \mathrm{p}<0.05$, Adjusted R-square $=0.23$ 


\section{DISCUSSION}

This is a first novel finding that the patients' perceptions of improvements in hand function were most strongly correlated with improvements only for tactile roughness discrimination acuity. Moreover, there were associations between finger pain and some sensory assessments.

Tactile roughness discrimination acuity likely showed the strongest correlation because the high-order sensory information processing function that is involved in discrimination of roughness, increases the patients' perception of their hands ${ }^{13)}$. Sensory function information processing only processes information related to the location on the body where the stimulus is introduced during single-point stimulus tests.

However, a previous study has shown that during tactile roughness discrimination tests, higher order information processing occurs, which, in addition to tactile roughness discrimination acuity, also discriminates the type of sensation being felt ${ }^{14)}$. Furthermore, brain activities of the superior parietal lobule, which processes higher order sensory information, are thought to be related to enhancing body schema imagery ${ }^{15)}$. Thus, the subjects' improvements in their perception of discriminating tactile roughness are related to brain activity that governs the perceptions of hand functions.

Otherwise, the finger pain assessed by PRWE was associated with both of the two-point discrimination tests. However, these assessments were not related to the perceptions of hand function. The tactile discrimination, pain, and two-point discrimination are all defined as sensory. However, these sensory tracts are different from each other ${ }^{16,17)}$. These findings may contribute to the present results; that only tactile discrimination tasks are associated with the patient's perception.

A causal relationship between an improvement in tactile roughness discrimination acuity and patient perception of hand function has still not been established, this is a limitation of the present study. In future studies, this causal relationship will have to be demonstrated through interventions targeting tactile roughness discrimination acuity during the immobile period.

\section{REFERENCES}

1) Harth A, Germann G, Jester A: Evaluating the effectiveness of a patient-oriented hand rehabilitation programme. $J$ Hand Surg Eur Vol, 2008, 33: 771-778. [Medline] [CrossRef]

2) Jester A, Harth A, Wind G, et al.: Disabilities of the arm, shoulder and hand (DASH) questionnaire: determining functional activity profiles in patients with upper extremity disorders. J Hand Surg [Br], 2005, 30: 23-28. [Medline] [CrossRef]

3) Wong JY, Fung BK, Chu MM, et al.: The use of disabilities of the arm, shoulder, and hand questionnaire in rehabilitation after acute traumatic hand injuries. J Hand Ther, 2007, 20: 49-55, quiz 56. [Medline] [CrossRef]

4) Yucel H: Factors affecting symptoms and functionality of patients with carpal tunnel syndrome: a retrospective study. J Phys Ther Sci, 2015, 27: 1097-1101. [Medline] [CrossRef]

5) Lee $\mathrm{S}$, Bae $\mathrm{S}$, Jeon $\mathrm{D}$, et al.: The effects of cognitive exercise therapy on chronic stroke patients' upper limb functions, activities of daily living and quality of life. J Phys Ther Sci, 2015, 27: 2787-2791. [Medline] [CrossRef]

6) Karadibak D, Yavuzsen T: Evaluation of kinesthetic sense and hand function in women with breast cancer-related lymphedema. J Phys Ther Sci, 2015, 27: 1671-1675. [Medline] [CrossRef]

7) Takashi N, Fujimoto S, Kon N, et al.: The factors related to the subjective hand function after hand surgery. J East Jpn Assoc Orthop Traumatol, 2014, 26: 421-424.

8) Imaeda T, Toh S, Wada T, et al. Impairment Evaluation Committee, Japanese Society for Surgery of the Hand: Validation of the Japanese Society for Surgery of the Hand Version of the Quick Disability of the Arm, Shoulder, and Hand (QuickDASH-JSSH) questionnaire. J Orthop Sci, 2006, 11: 248-253. [Medline] [CrossRef]

9) Bell-Krotoski JA, Fess EE, Figarola JH, et al.: Threshold detection and Semmes-Weinstein monofilaments. J Hand Ther, 1995, 8: 155-162. [Medline] [CrossRef]

10) Moberg E: Two-point discrimination test. A valuable part of hand surgical rehabilitation, e.g. in tetraplegia. Scand J Rehabil Med, 1990, 22: 127-134. [Medline]

11) Dellon AL: The moving two-point discrimination test: clinical evaluation of the quickly adapting fiber/receptor system. J Hand Surg Am, 1978, 3: 474-481. [Medline] [CrossRef]

12) Imaeda $T$, Uchiyama $S$, Wada $T$, et al. Clinical Outcomes Committee of the Japanese Orthopaedic Association and the Functional Evaluation Committee of the Japanese Society for Surgery of the Hand: Reliability, validity, and responsiveness of the Japanese version of the Patient-Rated Wrist Evaluation. J Orthop Sci, 2010, 15: 509-517. [Medline] [CrossRef] 
13) Eck J, Kaas AL, Mulders JL, et al.: The effect of task instruction on haptic texture processing: the neural underpinning of roughness and spatial density perception. Cereb Cortex, 2016, 26: 384-401. [Medline] [CrossRef]

14) Kitada R, Hashimoto $T$, Kochiyama $T$, et al.: Tactile estimation of the roughness of gratings yields a graded response in the human brain: an fMRI study. Neuroimage, 2005, 25: 90-100. [Medline] [CrossRef]

15) Sakata H, Takaoka Y, Kawarasaki A, et al.: Somatosensory properties of neurons in the superior parietal cortex (area 5) of the rhesus monkey. Brain Res, 1973, 64: 85-102. [Medline] [CrossRef]

16) Ghazni NF, Cahill CM, Stroman PW: Tactile sensory and pain networks in the human spinal cord and brain stem mapped by means of functional MR imaging. AJNR Am J Neuroradiol, 2010, 31: 661-667. [Medline] [CrossRef]

17) Paolucci T, Piccinini G, Paolucci S, et al.: Tactile and proprioceptive sensory stimulation modifies estimation of walking distance but not upright gait stability: a pilot study. J Phys Ther Sci, 2015, 27: 3287-3293. [Medline] [CrossRef] 